\title{
The Accuracy of an Intraoperative Frozen Section for Premalignant Endometrial Pathology
}

\author{
Ergul DEMIRCIVI BOR, Esra AKDENIZ², Yucel Nurettin CEYLAN', Taner GUNAY1, Meryem HOCAOGLU1, \\ Abdulkadir TURGUT ${ }^{1}$
}

Istanbul, Turkey

\begin{abstract}
OBJECTIVE: Abnormal uterine bleeding which is the most frequent complaint among pre- and postmenopausal women should be investigated to rule out endometrial cancer. An intra-operative frozen section can be taken to examine the suspicious of the malignancy. The study aims to investigate the accuracy of frozen section in suspicious of endometrial malignancy.

STUDY DESIGN: Fifty patients with pre-malign endometrial pathology and malignant ultrasound characteristics were included in this study and their preoperative biopsy, frozen and postoperative pathological results were examined.

RESULTS: The kappa coefficient between postoperative pathology and frozen section was 0.88 $(p<0.05)$ and $95 \%$ confidence interval was $(0.63-1.12)$. This indicates that the amount of agreement between the two tests was strong, thus the frozen section would be considered as a valid indicator of postoperative pathology results.
\end{abstract}

CONCLUSIONS: Frozen section is a valuable method to investigate the suspicious of malignancy in endometrial pre-malign lesions.

Keywords: Bleeding, Endometrium, Frozen, Hyperplasia, Section

Gynecol Obstet Reprod Med 20120;26(3):210-213

\section{Introduction}

Bleeding is the most frequent gynecological complain among pre- and postmenopausal women. The etiology of preand postmenopausal abnormal uterine bleeding (AUB) should be investigated using the PALM-COEIN system according to FIGO (1). Polyps, malignancy, and hyperplasia have been defined as the etiology of endometrium AUB by the PALM-

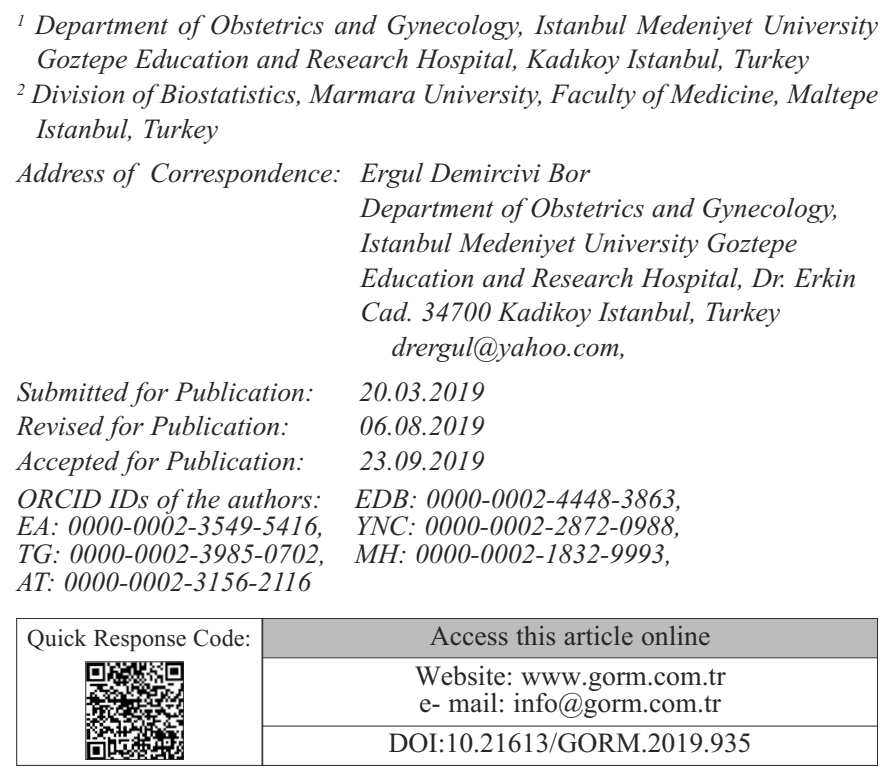

How to cite this article: Demircivi Bor E. Akdeniz E. Ceylan YN. Gunay T. Hocaoglu M. Turgut A. The Accuracy of an Intraoperative Frozen Section for Premalignant Endometrial Pathology. Gynecol Obstet Reprod Med. 2020; 26(3):210-213
COEIN system. However, in post-menopausal bleeding atrophy, malignancies and hyperplasia are the most common reasons for the AUB.

Given endometrial cancer is the most common gynecological cancer in developed countries, the possibility of malignancy should be ruled out while investigating the bleeding aetiologies (2). In atypical endometrial hyperplasia, the risk of malignancy can be increased by $30 \%(3,4)$. A common diagnostic problem may arise when atypical hyperplasia is seen in the preoperative biopsy. This makes difficult to distinguish between atypical hyperplasia and a well-differentiated adenocarcinoma, especially in small biopsy specimens.

Adenocarcinoma can be found in $17-43 \%$ of hysterectomy specimens performed for preoperative diagnosis of atypical hyperplasia (5). The main treatment for adenocarcinoma is total hysterectomy followed by a bilateral salpingo-oophorectomy (BSO), pelvic and para-aortic lymphadenectomy (6) and complete surgical staging if fertility is not a concern. An intraoperative pathological examination allows surgeons to decide about do or not to do the surgical staging (7). Frozen section is a rapid pathological examination of hysterectomy specimens by using a cryostat to provide result about malignancy during the operation. The frozen section has a high accuracy rate for high risk endometrial premalignant lesions and endometrial cancer staging $(8,9)$. However, the frozen section analysis was found low accuracy in patients with atypical endometrial hyperplasia (10). 
The present study aims to determine the accuracy of frozen section analysis to assess pre-malign endometrial lesions. The study also aims to understand the necessity to perform frozen section analysis where preoperative biopsy and ultrasound examination are available.

\section{Material and Method}

The present study was approved by the Hospital ethical committee with a number as 2017/0114 and conducted in accordance with the Declaration of Helsinki. The data were collected retrospectively from January 2010 and December 2016 and for this study consent for using data has given formally by the director of our clinic and hospital archive department. Fifty patients with pre-malign endometrial pathology and malignant ultrasound characteristics were included in this study based on the following criteria; irregular bleeding with endometrial thickness $>10 \mathrm{~mm}$ for pre-menopausal patients and irregularity with endometrial thickness $>4 \mathrm{~mm}$ for postmenopausal patients which all were approved clinically and histologically. The patients underwent surgery at the hospital as part of their treatment procedure. Ultrasonography examination, preoperative endometrial sampling, intra-operative frozen section analysis, and final histopathological evaluations were performed for all the patients.

Patients with the AUB, post-menopausal bleeding (PMB) and malign suspicious radiological imaging were also included. All the patients had an endometrial evaluation with radiological imagining and pathological sampling through dilatation and evacuation (C\&D). The pathological samples collected in Formol solution (Formaldehyde) and the results were reported according to the World Health Organisation (WHO) classification (11).

Hysterectomy with or without oophorectomy was the firstline treatment for all patients with pre-malign lesions in preoperative sampling or suspicious pre-malignant ultrasonography. Frozen section samples were grossly examined and macroscopically suspicious lesions were sampled. The frozen section results reported as malign or non-malign. The final histopathological examination of operation materials reported according to WHO and FIGO classifications (12).

Statistical analyses were performed using $\mathrm{R}$ Statistical Software (The R Foundation). The categorical variables were defined as frequencies and percentages (\%). Cohen kappa statistic was used for measuring agreement between frozen section and postoperative (13). Cohen's kappa coefficient was calculated with ckap function in rel package in $\mathrm{R}$ program. $P<0.05$ was considered statistically significant.

\section{Results}

The patients' median age was $51 \pm 8.9$. Descriptive results are at table I. Our all benign biopsy resulted in patients had pathological ultrasonography findings.
Table I: Descriptive statistics for patients

\begin{tabular}{lll}
\hline Variables & Categories & $\mathbf{n}(\%)$ \\
\hline Complains of patients & Postmenopausal bleeding & $16(32)$ \\
& Abnormal uterine bleeding & $28(56)$ \\
& Pain & $6(12)$ \\
Imaging study & Normal & $21(42)$ \\
& Abnormal Ultrasonography & $29(58)$ \\
Preoperative Biopsy & Benign & $33(66)$ \\
& Insufficient & $8(16)$ \\
Frozen section & Premalignant & $9(18)$ \\
& Benign & $46(92)$ \\
Postoperative pathology & Benign & $4(8)$ \\
& Malign & $44(88)$ \\
& & $6(12)$ \\
\hline
\end{tabular}

Precisely patient base results were given at table II. Eight patients with insufficient preoperative biopsy results were excluded from the study. Total of 50 patients with preoperatively diagnosed was screened (known biopsy results). The kappa coefficient between postoperative pathology and frozen section was $0.88(p<0.05)$ and $95 \%$ confidence interval was $(0.63-$ 1.12). This indicates that the amount of agreement between the two tests was strong, thus the frozen section would be considered as a valid indicator of postoperative pathology results.

Table II: Patient base results

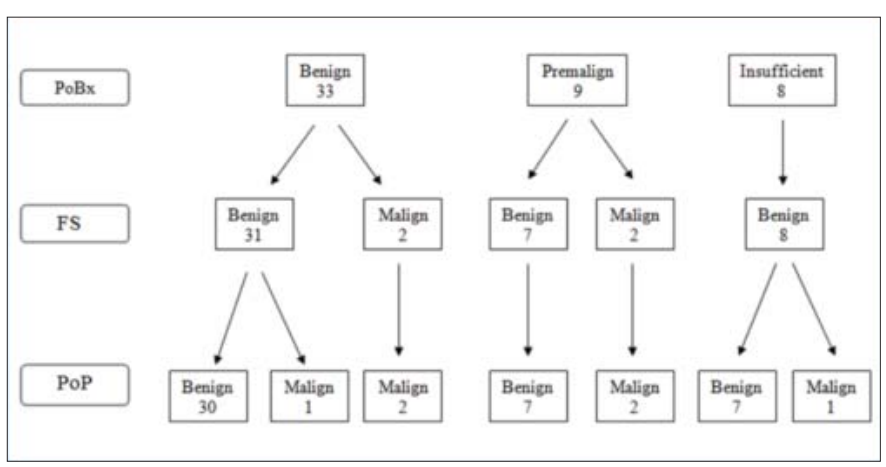

The kappa coefficient between preoperative biopsy and frozen section was $0.20(p>0.05)$ and the $95 \%$ confidence interval was $(-0.27,0.68)$. This indicates that the amount of agreement between the two tests was weak.

The kappa coefficient between preoperative biopsy and postoperative pathology was $0.16(p>0.05)$ and the $95 \%$ confidence interval was $(-0.31,0.63)$. This indicates that the amount of agreement between the two tests was weak.

Frequencies of preoperative biopsy and frozen section versus postoperative pathology which is considered as a gold standard are given in table III. According to table III, the sensitivity, specificity, negative and positive predictive value for the frozen test was found as $0.67,1,0.96$, and 1 , respectively. The diagnostics results for the frozen test are inconsistent with the kappa statistic in terms of the agreement. 
Table III: Frequencies (\%) of preoperative biopsy and frozen section versus postoperative pathology (Totally 42 patients whose results are benign or malign preoperatively are considered).

\begin{tabular}{lclcl}
\hline & Preoperative (Benign) & Preoperative (Malign) & Frozen (Benign) & Frozen (Malign) \\
\hline Postoperative (Benign) & $30(91 \%)$ & $7(78 \%)$ & $44(96 \%)$ & 0 \\
Postoperative (Malign) & $3(9 \%)$ & $2(22 \%)$ & $2(4 \%)$ & $4(100 \%)$ \\
\hline
\end{tabular}

According to table III, the sensitivity, specificity, negative predictive value, and positive predictive value for pre-op were found as $0.40,0.81,0.91$, and 0.22 , respectively. The diagnostics results for pre-op are inconsistent with the kappa statistic in terms of disagreement.

\section{Discussion}

The present study showed that the frozen section analysis can be used as a reliable procedure in patients with pre- or postmenopausal AUB. The risk of malignancy is the main reason for the preoperative dilatation and curettage (D\&C) in preor postmenopausal AUB cases.

In menopausal age women, preoperative sampling is shown as a highly accurate and effective method to detect malignancy $(14,15)$. However, preoperative biopsies (PoBx) is found accurate by nearly 60 percent (16), in some cases, PoBx is benign whereas ultrasonographic findings show malignant features. In patients with post-menopausal bleeding, sensitivity and specificity of transvaginal ultrasonography (TSVU) have been found as sensitive as endometrial cytology and D\&C to detect pathological alterations (17) Malignancy can be ruled out safely where the sonographic endometrial thickness is $<$ or $=4.0 \mathrm{~mm}$ (18).

In the present study, there were two patients who were missed preoperatively and at frozen section one was diagnosed as benign and the other was inadequate sampling. However, both of them were diagnosed with pathologically at the ultrasonographic examination. Sampling failure can be seen in twenty percent of endometrial samples (19). In this study, there were three patients that their endometrial sampling results became benign and the final results were upgraded to malign by frozen examination $(n=2)$ and postoperative pathology $(\mathrm{n}=1)$.

The final result was also upgraded to malignant by postoperative pathology in a patient with insufficient endometrial sampling. The present study showed a low diagnostic sensitivity preoperatively $(0.40)$. The study included the patients with suspicious ultrasound features and insufficient endometrial sampling, which can be the main reason for decreasing sensitivity in the preoperative sampling procedure.

Frozen section analysis is a highly reliable intra-operative pathological procedure, which has an important role in the management of surgical patients. The technique is used to determine pre-malignant and malignant endometrial lesions to make a decision on the necessity of dissecting the lymph nodes (lymphadenectomy) during surgical staging $(9,20)$. The frozen section analysis was performed for the patients with pre-malignant preoperative pathology and malignant ultrasonographic features, which had either benign or insufficient preoperative pathologic results.

There was a strong correlation between frozen section analysis and postoperative result in the present study. The postoperative results were compatible with two malignant patients in the frozen section who were malignant, but their myometrial invasion was less than $\% 50$ of myometrial thickness and lymphadenectomy was not needed. The frozen section analysis was considered as an unreliable predictor or unnecessary to rule out malignancy by some studies $(21,22)$. However, the present shows that frozen section is needed in particular for insufficient preoperative biopsy or ultrasonographically suspicious of malignancy but preoperatively benign biopsy patients. The procedure was also found as a reliable method to detect endometrial malignancy by other studies $(20,23)$ especially in patients with premalignant preoperative biopsy results $(8,24)$.

In conclusion, the frozen section assessment of hysterectomies for preoperative diagnosis of atypical hyperplasia or suspicion of malignancy may be helpful to identify the significant fraction requiring lymphadenectomy and spare low-risk patients the morbidity of lymphadenectomy. The present study is limited by the small sample size in which it was not possible to divide the patients into pre- and postmenopausal subgroups. Therefore, it is suggested to carry out the study in a larger sample size.

Acknowledgment: None

Conflict of interest: All the authors have no conflict of interest.

Funding: None

Author Contribution: EDB: Corresponding writer, study development and idea support, paper writing, EA: Statistical analysis, study development, paper writing, YNC: Data collection, paper writing, TG: Study development, paper writing, MH: Study development, paper writing, AT: Study development and idea support, paper writing.

\section{References}

1. Munro MG, Critchley HO, Broder MS, Fraser IS; FIGO Working Group on Menstrual Disorders. The FIGO Classification System ("PALM-COEIN") for causes of abnormal uterine bleeding in non-gravid women in the reproductive years, including guidelines for clinical investi- 
gation. Int J Gynaecol Obstet. 2011;113(1):3-13. doi.org/ 10.1016/j.ijgo.2010.11.011

2. U.S. Cancer Statistics Working Group. United States Cancer Statistics: 1999-2014 Incidence and Mortality Web-based Report.

3. Kurman RJ, Kaminski PF, Norris HJ. The behaviour of endometrial hyperplasia: a long-term study of 'untreated' hyperplasia in 170 patients. Cancer. 1985;56(2):403-12. doi.org/10.1002/1097-0142(19850715)56:2<403:AIDCNCR2820560233>3.0.CO;2-X

4. Widra EA, Dunton CJ, McHugh M, Palazzo JP. Endometrial hyperplasia and the risk of carcinoma. Int $\mathrm{J}$ Gynecol Cancer.1995;5(3):233-5. dx.doi.org/10.1046/j. 1525-1438.1995.05030233.x

5. Janicek MF, Rosenshein NB. Invasive endometrial cancer in uteri resected for atypical endometrial hyperplasia. Gynecol Oncol. 1994;52(3):373-8. doi.org/10.1006/gyno. 1994.1064

6. American College of Obstetricians and Gynecologists. ACOG practice bulletin, clinical management guidelines for obstetrician-gynecologists, number 65, August 2005: management of endometrial cancer. Obstet Gynecol. 2005;106(2):413-25. doi: 10.1097/00006250-20050800000050 .

7. El-Bahrawy M, Ganesan R. Frozen section in gynaecology: uses and limitations. Arch Gynecol Obstet. 2014; 289(6):1165-70. DOI: 10.1007/s00404-013-3135-y

8. Gungorduk K, Ozdemir A, Ertas IE, Sahbaz A, Asicioglu O, Gokcu M, et al. A novel preoperative scoring system for predicting endometrial cancer in patients with complex atypical endometrial hyperplasia and accuracy of frozen section pathological examination in this context: a multicenter study. Gynecol Obstet Invest. 2015;79(1):50-6. DOI: $10.1159 / 000365086$

9. Wang X, Li L, Cragun JM, Chambers SK, Hatch KD, Zheng W. Assessment of the role of intraoperative frozen section in guiding surgical staging for endometrial cancer. Int J Gynecol Cancer. 2016;26(5):918-23. DOI: 10.1097/ IGC.0000000000000692

10. Bilgin T, Ozuysal S, Ozan H, Atakan T. Coexisting endometrial cancer in patients with preoperative diagnosis of atypical endometrial hyperplasia. J Obstet Gynaecol Res. 2004;30(3):205-9. DOI: 10.1111/j.1447-0756.2004. 00178.x

11. Silverberg SG, Kurman RJ, Nogales F, Mutter GL, KubikHuch RA, Tavassoli FA. Epithelial tumors and related lesions of endometrium. In: Tavassoli FA, Stratton MR, editors. Tumors of the breast and female genital organs. Lyon: IARC Press, 2003; p: 221-32.

12. Mutch DG The New FIGO staging system for cancers of vulva, cervix, endometrium and sarcomas. Gynecol Oncol. 2009;115;325-8. DOI:10.1016/j.ygyno. 2009.10. 050

13. Cohen, J. A coefficient of agreement for nominal scales.
Educ Psychol Meas. 1960;20(1):37-46. doi.org/ 10.1177/ 001316446002000104

14. Barut A, Barut F, Arikan I, Harma M, Harma MI, Ozmen Bayar U.Comparison of the histopathological diagno $\neg$ ses of preoperative dilatation and curettage and hyste $\neg$ rectomy specimens. J Obstet Gynaecol Res. 2012;38(1):1622. doi: 10.1111/j.1447-0756.2011.01633.x.

15. Yarandi F, Izadi-Mood N, Eftekhar Z, Shojaei H, Sarmadi S. Diagnostic accuracy of dilatation and curettage for abnormal uterine bleeding. J Obstet Gynaecol Res 2010; 36(5):1049-52. doi: 10.1111/j.1447-0756.2010.01288.x.

16. Batista TP, Cavalcanti CL, Tejo AA, Bezerra AL. Accuracy of preoperative endometrial sampling diagnosis for predicting the final pathology grading in uterine endometrioid carcinoma. Eur J Surg Oncol. 2016;42(9): 1367-71. doi: 10.1016/j.ejso.2016.03.009.

17. Karlsson B, Granberg S, Wikland M, Ryd W, Norström A. Endovaginal scanning of the endometrium compared to cytology and histology in women with postmenopausal bleeding. Gynecol Oncol. 1993;50(2):173-8. doi: 10.1006 /gyno.1993.1188.

18. Bakour SH, Dwarakanath LS, Khan KS, Newton JR, Gupta JK. The diagnostic accuracy of ultrasound scan in predicting endometrial hyperplasia and cancer in postmenopausal bleeding. Acta Obstet Gynecol Scand. 1999;78(5):447-51.

19. Dijkhuizen FP, Mol BW, Brölmann HA, Heintz AP. The accuracy of endometrial sampling in the diagnosis of patients with endometrial carcinoma and hyperplasia: a meta-analysis. Cancer. 2000;89(8):1765-72.

20. Attard Montalto S, Coutts M, Devaja O, Summers J, Jyothirmayi R, Papadopoulos A. Accuracy of frozen section diagnosis at surgery in premalignant and malignant lesions of the endometrium. Eur J Gynaecol Oncol. 2008;29 (5):435-40. doi: 10.1097/01.AOG.0000465189.50026.20.

21. Indermaur MD, Shoup B, Tebes S, Lancaster JM. The accuracy of frozen pathology at time of hysterectomy in patients with complex atypical hyperplasia on preoperative biopsy. Am J Obstet Gynecol. 2007;196(5):e40-e42. doi: 10.1016/j.ajog.2006.10.886.

22. Kumar S, Bandyopadhyay S, Semaan A, Shah JP, Mahdi $\mathrm{H}$, Morris R, et al. The role of frozen section in surgical staging of low risk endometrial cancer. PLoS One. 2011;6(9):e21912. doi: 10.1371/journal.pone.0021912.

23. Oz M, Ozgu E, Korkmaz E, Bayramoglu H, Erkaya S, Gungor T. Utility of frozen section pathology with endometrial pre-malignant lesions. Asian Pac J Cancer Prev. 2014;15(15):6053-7. doi: 10.7314/apjcp.2014.15.15.6053

24. Gunay T, Yardımcı OD, Şentürk MB, Polat M, Güzin K. Comparison of frozen and final histopathology results in cases with endometrial hyperplasia: seven-year experience of a tertiary center. IKSST Derg. 2018;10(2):65-9. doi:10.5222/iksst.2018.18189 